\title{
Effect of Microstructure on Wear Resistance of Low-Alloy High-Strength Wear-Resistant Steel
}

\author{
Dongting $\mathrm{Wu}^{1}$, Hui Zhang ${ }^{1,2}$, Shushuai Liu ${ }^{1}$, Yuanxiao $\mathrm{Li}^{3}$, Zhiqiang $\mathrm{Li}^{4, *}$ Yong Zou ${ }^{1 *}$ \\ ${ }^{1}$ Key Laboratory for Liquid-Solid Structural Evolution and Processing of Materials, Ministry of \\ Education, Shandong University, Jinan 250061, China \\ ${ }^{2}$ School of Mechanical and Automotive Engineering, Qilu University of Technology, Jinan 250353, \\ China \\ ${ }^{3}$ Shandong Institute for Products Quality Inspection, Jinan 250100, China \\ ${ }^{4}$ Center for Optics Research and Engineering (CORE), Shandong University, Qingdao 266237, China. \\ *E-mail: yzou@sdu.edu.cn
}

doi: $10.20964 / 2019.08 .20$

Received: 8 March 2019 / Accepted: 29 May 2019 / Published: 30 June 2019

In this paper, microstructure, corrosion resistance and wear resistance of low-alloy high-strength wearresistant steels of NM400 and KN400X were studied. It is found that the wear resistance of these steels differed from each other significantly although their chemical compositions were similar, depending on microstructure, grain size and non-metallic inclusions. The results of the tests on corrosion resistance and wear resistance showed that the KN400X steel had the best performance in both properties. Lower content of non-metallic inclusions resulted in more uniform and compact microstructure, which together with better corrosion resistance led to better abrasive wear property.

Keywords: wear resistance; microstructure; Electrochemical; corrosion resistance

\section{FULL TEXT}

(C) 2019 The Authors. Published by ESG (www.electrochemsci.org). This article is an open access article distributed under the terms and conditions of the Creative Commons Attribution license (http://creativecommons.org/licenses/by/4.0/). 